\title{
Review of the study on macro-mechanical characteristics of wet concrete and their analysis methods
}

\author{
Hongbiao Liu", a * \\ ${ }^{1}$ Tianjin Research Institute for Water Transport Engineering, MOT, Tianjin 300456, China \\ aemail:liuhbhit@hotmail.com
}

Keywords: Review, Wet concrete, Macro-mechanical characteristics, Meso-mechanical analysis method, Meso-mechanics.

\begin{abstract}
Macro-mechanical properties of wet concrete are important for concrete structure design because the pore saturation in concrete has great influence on the mechanical properties of concrete. The research states of macro-mechanical characteristics of wet concrete were introduced in the filed of tests and meso-mechanical analysis methods. The test research achievements and application of meso-mechanical analysis methods on macro-mechanical characteristics of wet concrete were stated. The factors influencing the macro-mechanical characteristics of wet concrete were provided. Finally, the research trends on macro-mechanical properties of wet concrete in experiment and meso-mechanical analysis theory, as well as the problems to be solved are pointed out and prospected based on above.
\end{abstract}

\section{Introduction}

The macro-mechanical parameters of wet concrete are very important for concrete structure design of harbor engineering. The concrete of structures working in seawater environment chronically, such as wharf and offshore structures, cross-sea bridge, offshore oil platform, is in the saturated or half saturated state due to the surrounding water pressure and the initial defects of various internal micro cracks and pores. The free water in concrete pores will produce water pressure to the pore wall under different loads, which will influence the macro-mechanical properties of concrete. Compared with the dry concrete, static strength of saturated concrete decreased. However, it will takes a long time for concrete from the dry state to saturated state, even taking many years, so the macro-mechanical properties of wet concrete and the time-varying rules in the process of concrete from dry to saturated are concerned.

The research achievements on the time-varying rules and meso-mechanical analysis methods of macro-mechanical characteristics of wet concrete in marine environment are provided detailedly in this paper. The description is stated from two aspects that experiment research states and meso-mechanical analysis theories research state of macro-mechanical properties of wet concrete. Based on above, the simple description for the development direction of macro-mechanical properties research and problems to be solved in the further are provided.

\section{Experimental study of wet concrete mechanical properties}

The concrete of structure working in seawater environment chronically is often thought being in saturated state. In the past few years, the saturated concrete is always selected as the study object for scholars in the research of concrete mechanical performance in harbor engineering. At present, the macro-mechanical property study of saturated concrete has gotten studied in depth, and many achievements have been made in the macro-mechanical properties test of saturated concrete and meso-mechanical theory [1-6]. Based on the experiments, Powers (1946) and Yaman (2002) pointed out that the static strength of saturated concrete decreased and the elastic modulus and Poisson's ratio increased comparing with the dry concrete $[1,2,7]$. Wang (2007) carried out the study on varying rules of compressive performance of saturated concrete and splitting tensile performance under different loading rate through the material mechanics experiment of concrete, and the test results show 
that the compressive strength and splitting strength of saturated concrete decreased under quasi-static loading compared with the dry concrete. However, compressive strength and splitting tensile strength greatly increased with loading velocity increasing [8-9]. Concrete from the dry state to the saturated state will take a long time. Persson (1997) found that the maximum saturation of the concrete is only $98 \%$ and less than $100 \%$ even though concrete was in water for a long time [10]. Chatterji (2004) found in the test that the inner of cylindrical section of concrete specimen with a 17 inch diameter is still dry after it was immersed in water 222 days. Ge (2007) pointed out by mechanism analysis that the adsorption ability of water is poor and diffusion of water in concrete is slow due to the concrete gel pores in saturated state, so concrete is difficult to achieve the saturated state under normal atmospheric pressure [11]. Therefore, the macro-mechanical properties of concrete in unsaturated state are concerned by scholars. Based on Yaman's experimental results, Wang (2007) established the meso two-stage equivalent model using two-phase combination theory, and the prediction of concrete elastic modulus and Poisson's ratio of unsaturated concrete is realized [12]. Du (2013) established the three-phase sphere model based on two-phase combination theory and the inclusion theory, and realized the prediction of macro-mechanical properties of unsaturated concrete, such as elastic modulus, Poisson's ratio and peak tensile compressive strain. However, systematic experimental study for the macro-mechanical properties of unsaturated concrete is lacking at present, and it difficult to have a comprehensive understanding on the varying law of macro-mechanical properties of unsaturated concrete with time, and also the mechanical parameters on the specification from dry concrete cannot be revised.

The mechanical properties of wet concrete are different from the dry concrete. Moisture content of the concrete has great influence on its strength, elastic modulus, Poisson's ratio and other parameters [13-14]. Cadoni (2001) carried out the material mechanical experiment of concrete specimens which was immersed in water after curing 90 days and the test showed that the tensile strength of concrete decreased from 3.28MPa in dry state to $3.02 \mathrm{MPa}$ in saturated state [15], and the fall rate is $7.62 \%$. Based on the material test, Yaman (2002) pointed out that the elastic modulus and Poisson's ratio of saturated concrete are larger than that of the dry concrete [1], and the increment is from $6 \%$ to $25 \%$. Yan (2005) carried out the tensile experiment of concrete specimens which were put in the water for 60 days after curing 300 days [13], and the test results show that when water content of concrete changes from $0.31 \%$ to $4.8 \%$, the tensile strength decreases from $2.21 \mathrm{MPa}$ to $1.30 \mathrm{MPa}$, decreasing by $41.2 \%$. Wang (2007) pointed out based on the static material test that after concrete specimens were immersed in water for 48 days, the compressive strength and splitting tensile strength of wet concrete decreased $4.5 \%$ and $11.41 \%$ respectively compared with the dry concrete [8-9]. Li (2007) carried out the three-axis compressive test of 20 concrete specimens immersed in water for 1050 days with different pressure and the test results show that the strength of the concrete decreased greatly compared with the dry concrete [16]. Li (2011) carried out the static compressive test of C25 concrete specimens which were immersed in water 28 days, and the compressive strength decreased $30.2 \%$ compared with the dry concrete [17]. Wittmann (2007) pointed out that the strength of concrete immersed in $\mathrm{NaCl}$ solution for a long time decreased observably based on the material test [18]. But in tests above, the assumption is that the concrete specimens got in the saturated state after they were immersed in water for a short time. However, the fact is not that. Powers (1946) found that part of the interior specimen is still in dry after the cement mortar specimens were immersed in water for 220 days [7]. Material tests by Neville also showed that the area whose humidity changed in the round specimen with 4 inch diameter only accounted for $12 \%$ of the cross-sectional area after the specimens were immersed for 2 days [19]. Vu (2009) carried out the static compressive test for concrete specimens with different saturation degree, and the test results show that the compressive strength are $42 \mathrm{MPa}, 34 \mathrm{MPa}$ and $32 \mathrm{MPa}$ when the concrete saturation are $11 \%, 42 \%$ and $100 \%$, respectively [20]. Ji (2010) pointed out that water saturation of concrete strength is determined by concrete strength and the external environment of concrete through the material test [4]. Li (2011) carried out the compressive tests for C20, C25, C30 concrete specimens which were immersed in water for 1 day, 3 days 7 days, 14 days, 28 days respectively, and got the varying laws and relevant mechanism of concrete strength with different 
saturation [17]. At present, there is little experimental study on macro-mechanical properties of unsaturated concrete and it is not sufficient for understanding macro-mechanical properties of unsaturated concrete.

The macro-mechanical parameters of concrete are key points for seismic design, numerical simulation and safety assessment of harbor concrete structure. If parameters of concrete are not accurate, the calculation results will be not accurate, and structural safety assessment may be uncorrected based the calculating results. In order to ensure the service life of harbor structure and be make the dynamic response simulation of structure more accurate and reliable under complex loads, the study on macro-mechanical properties of unsaturated concrete and their varying rules in process to be saturated is urgently demanded at present..

\section{Meso-mechanical analysis method of wet concrete}

Based on the feature size and different analysis methods, the structure of materials can be divided into three levels, which are macro structure, meso structure and micro structure. Macro structure is the structure which is can be seen by eyes or magnifier. Meso structure is the structure which can be distinguished with light microscope. Micro structure is structure in the atom or molecular level. At present, the study on mechanical properties of concrete materials and the constitutive relationship is carried out in the two levels of macro and meso. However, generally the assumption of isotropy continuum material is used to analysis mechanics performance of concrete or concrete structure. In fact, the model established based on the assumption cannot reflect the internal structure, composition of concrete with its mechanical properties, and also it can not explain the crack propagation process reasonably. So it is difficult to explain the local damage caused by local stress concentration and concrete small crack in the meso view.

The development of meso-mechanical theory and computer technology provides new ways for the study on the relationship between meso-structure of concrete and the macro-mechanical properties of concrete. Concrete can be regarded as multiphase composite material made of matrix, coarse and fine aggregates, transition interfacial zone and pore in meso level. It has been the focus of research field of concrete material properties that how to analysis the macro mechanical properties of concrete from in meso level and to establish the analysis method in meso-mechanical.

Currently, the study on the macro-mechanical properties of wet concrete in meso-level is carried out based on the assumption that the concrete is in saturated state. Yaman (2002) predicted the elastic modulus of saturated concrete using the equivalent composite material method established based on the Mori-Tanaka method and Kuster-Toksoz theory [2]. Mori-Tanaka method is a method to calculate the elastic modulus of non-homogeneous material, which was established by Mori and Tanaka in 1973 based on Eshelby equivalent inclusion principles [21]. In this method, the fourth-order tensor between the average strain of mixed phase and average strain of matrix phase was established, and the fourth-order tensor which is determined by the concentration of inclusions in matrix material is replaced by the connection tensor between the average strain of single inclusion and homogeneous strain within the infinite base material. The method has become one of the main means to predict the performance of inhomogeneous composites materials at present, but the method is only applicable for the case of small inclusion content. Karastathis (2002) evaluated the dynamic characteristics of highly saturated concrete based on unilateral acoustic tomography method [22]. Macro-mechanical properties of concrete are determined by its meso-structure. Guo, Wang and Bai have done the study on the varying mechanism of macro-mechanical properties of wet concrete in meso-mechanical filed. Guo (2001) established mathematical model based on elastic mechanics and the reason why the compressive strength decreased of wet concrete and modulus increased was explained with it. The method is particularly suitable to analysis the surface stress of saturated pores in concrete [23]. Wang (2005, 2006 and 2008) pointed out that the pore water pressure is the main factor causing the wet concrete strength decreasing, and the model was established based on meso inclusions theory and Mori-Tanaka method to predict the influence of pore water to the elastic modulus of wet concrete. 
Meanwhile, the mechanism was proposed to explain why compressive strength and tensile strength decreased. The study showed that the pore water pressure in concrete reduced the friction resistance of concrete cracking, which was like "wedge" effect of wedge to accelerate the expansion of micro-cracks in the concrete, and resulted in concrete compressive strength and tensile strength decreasing. But under the fast-loading pore water in the concrete cracks is more difficult to achieve crack tip, which makes concrete affected by negative pore water pressure and Stefan affect, so dynamic compressive strength of saturated concrete rose fast [8-9, 24-28]. Bai (2009) established the uniaxial tension dynamic statistical damage constitutive model based on Terzaghi effective stress theory to describe the damage evolution mechanism of saturated concrete in meso view [29]. Yuan (2011) carried out the study on the spread mechanism of chloride ion in saturated concrete [30]. It will takes long time to reach saturated for concrete, and many achievements on study of mechanical behavior of unsaturated concrete have made at present. Bourgeois (2002) proposed the elastoplastic model for the effective mechanical properties of saturated and unsaturated rock as well as concrete based on the porous flexible theory of porous material, and analyzed the effects of different moisture content to the mechanical properties of concrete and rock [31]. Chatterji (2004) presented theoretical interpretation why concrete was in half-saturated or non-saturated in water [32]. Wang (2007) predicted the effective elastic modulus and Poisson's ratio of unsaturated concrete with taking into account the viscous effects of water [12]. Bai (2008) established the double inclusion model by setting the active gap, inactive voids and cement mortar as the equivalent matrix and setting the coarse aggregate as a kind of hardened inclusion based on equivalent inclusion theory and Mori-Tanaka mean-field theory, and the uniform uniaxial compressive strength formulas of concrete which can consider a variety of factors was proposed based on the meso fracture mechanics methods. It can predict the compressive strength of wet concrete. Meanwhile, the formula can analyze the relationship of concrete strength with porosity, mortar and aggregates, and the analysis results show that the concrete strength is controlled by weaker phase between the aggregate and cement mortar. Water in the pore will cause wet concrete compressive strength decreasing compared with dry concrete [3]. Ghabezloo (2010) carried out the compression tests of mortar under water drainage and undrained, and the porous elastic parameters of grout material were evaluated with the use of multi-scale homogenization method [33]. Jin (2012) studied the influence of porosity to the effective bulk modulus and elastic modulus of saturated concrete with three-phase sphere model and cylindrical hollow rod model, and based on the assumption that the pore water did not have shear resistance, the effective elastic modulus and Poisson's ratio of saturated concrete were gotten [34]. Li (2012) established the wet concrete strength calculation model based on probability theory and reliability theory [14]. Du (2013) assumed the unsaturated concrete as a multi-phase composite material made of matrix, pore water, dry and unsaturated porous in meso view, and the two-step homogenization method to predict the macro-mechanical properties of unsaturated concrete was proposed. The quantitative relationship of porosity and saturation with the elastic modulus, Poisson's ratio, tensile strength and tensile peak strain of wet concrete was identified initially. The analysis results show that wet concrete elastic modulus, Poisson's ratio, tensile strength and tensile strain increase with saturation increasing, and the strength of concrete in low saturation decreased with concrete porosity increasing. However, the peak tensile strain of concrete in high saturation decreased firstly and then increased with porosity increasing based on analysis [35].

\section{The trend of development}

At present, it is short of comprehensive and systemic research for the macro-mechanical properties of unsaturated concrete. In the aspect of experiment, the test data to verify the meso-mechanical analysis model is almost from just one scholar experiment, and the data is insufficient slightly. In order to fully understand the macro-mechanical properties of unsaturated concrete, the comprehensive and systematic material experiments for wet concrete mechanical properties should be done to provide the adequate and reliable test data for the meso-mechanical theory research of wet concrete. In the aspect of meso-mechanical analysis theory, the current analytical methods are just for the analysis and 
prediction of macro-mechanical properties of dry concrete or saturated concrete, in which the effect of unsaturated pore water and the saturation of concrete to the macro-mechanical properties of concrete is not considered. In order to analyze the macro-mechanical properties of unsaturated concrete with meso-mechanical theory, the study on the meso-mechanical analysis theory considering the saturation, unsaturated pore and pore water should be carried out to realize the analysis and prediction of wet concrete mechanical properties based on assumption of multi-phase composite theory. In the aspect of meso-mechanics finite element analysis method, it is difficult to simulate the unloading process for the current finite element calculation method, while the computational model is difficult to consider the impact of non-saturated pore water. In order to achieve the simulation of non-saturated concrete macro-mechanical properties and fracture process, it is necessary to carried out the study on numerical methods of wet concrete considering the pore water effects based on the random aggregate model and composite material equivalent theory.

\section{Conclusions}

Macro-mechanical properties of concrete are very important and essential parameters for concrete structure design and numerical analysis. Macro-mechanical properties of unsaturated concrete are determined by its meso-structure. The research status of macro-mechanical properties of wet concrete and meso-mechanical analysis methods are described based on the review of study on the mechanical test and meso-mechanical theory of wet concrete, and the conclusions are summarized as follows:

1) Macro-mechanical properties of wet concrete are affected by many factors, such as pore water, saturation and porosity of concrete. Currently, there are insufficient experiments for wet concrete and the macro-mechanical property data of wet concrete is not enough. Meanwhile, it will take a long time for concrete from dry state to saturated state, and adequate test data is necessary to clear the law that macro-mechanical properties of concrete vary with its saturation. Therefore, comprehensive and systematical mechanical testing is essential for the research work of wet concrete macro-mechanical properties.

2) Meso-mechanical analysis theory is a necessary means for analyzing wet concrete macro-mechanical properties. Concrete in the water environment is suffered the external water pressure, pore water pressure and other loads, and the current meso-mechanical thoey established based on the assumption of multi-phase composite materials can not consider the impact of unsaturated pore water pressure. So the related research should be taken in order to analysis the macro-mechanical properties of wet concrete in meso-mechanical view.

\section{Acknowledgments}

This work was financially supported by the National Higher-education Institution General Research and Development Funding (TKS140101, TKS150208) and the Information Science and Technology Project of M.O.T (2013-364-224-700).

\section{References}

[1] Yaman I O , Hearn N and Aktan H M, "Active and non-active porosity in concrete part I: experimental evidence", Materials and Structures, vol.35, no.2, pp.102-109, 2002.

[2] Yaman I O, Aktan H M and Hearn N, "Active and non-active porosity in concrete part II: evaluation of existing models", Materials and Structures, vol.35, no.2, pp.110-116, 2002.

[3] W.F Bai, J.Y Chen and S.L Fan, "Prediction of compressive strength of moisture concrete by meso-inclusion theory", Engineering Mechanics, vol.25, no.11, pp.134-140, 2008.

[4] Y.S. Ji, W. Si, Y.S. Yuan, et al, "Experimental research on degree of pore saturation in concrete", Sichuan Building Science, no.1, pp.166-168, 2010. 
[5] D. Zheng and X.X. Li, "Review of researches on influences of pore water on static properties of concrete", Advances in Science and Technology of Water Resources, vol.31, no.1, pp.90-94, 2011.

[6] X.L. Du and L. Jin, "Micro-scale homogenization for prediction of the macroscopic mechanical properties of unsaturated concrete", SHUI LI XUEBAO, vol.44, no.11, pp.1317-1325, 2013.

[7] T.C. Powers and T.L. Brownyard, "Studies of the physical properties of hardened Portland cement paste", Proceedings of Journal of American Concrete Institute, vol.43, no.9, pp.101-132.

[8] H.L. Wang and Q.B. Li, "Experiments of the compressive properties of dry and saturated concrete under different loading rates", Journal of Hydroelectiuc Engineering, 2007, vol.26, no.1, pp.84-89.

[9] H.L. Wang and Q.B. Li, "Experiments on saturated concrete under different splitting tensile rate and mechanism on strength change", ENGINEERING MECHANICS, vol.24, no.2, pp.105-109, 2007.

[10]Persson B, "Moisture in concrete subjected to different kinds of curing", Materials and Structures, vol.30, no.9, pp.533-544, 1997.

[11]Y. Ge, Y.Y. Sun, J. Yuan, et al, "Study on the degree of concrete saturation”, Low Temperature Architecture Technology, no.6, pp.1-3, 2007.

[12]H.L. Wang and Q.B. Li, "Prediction of elastic modulus and Poisson's ratio for unsaturated concrete", International Journal of Solid and Structures, vol.44, no.5, pp.1370-1379, 2007.

[13]D.M. Yan, G. Lin, Z. Wang, et al, "Research on dynamic direct tensile properties of concrete under different environments", Journal of Dalian University of Technology, vol.45, no.3, pp.416-421, 2005.

[14]X.X. Li, and D. Zheng, Wet concrete strength model based on reliability analysis", ENGINEERING MECHANICS, vol.29, no.5, pp.161-165, 2012.

[15]E. Cadoni, K. Labibes, C. Albertini, et al, "Strain-rate effect on the tensile behavior of concrete at different relative humidity levels", Materials and Structure, vol.34, no.1, pp.21-26, 2001.

[16]Q.B. Li, Z.F.S. Chen, M.Y. Sun, et al, "Effect of water loading on strength of concrete", SHUILI XUEBAO, vol.38, no.7, pp.786-791, 2007.

[17]X.X. Li, "Pore water influence to static mechanical properties of concrete", M.S. thesis, Chongqing Jiaotong University, Chongqing on China, 2011.

[18]F.H. Wittmann, Z. Sun, T. Zhao, "Strength and fracture energy of concrete in seawater" in Proceedings of Framcos-6 Fracture Mechanics of Concrete and Concrete Structures, 2007, pp.213-217.

[19]A.M. Neville, Properties of concrete, London: Pitman Publishing Ltd, 1981.

[20]X.H. Vu, Y. Malecot, L. Daudeville, et al, "Experimental analysis of concrete behavior under high confinement: Effect of the saturation ratio", International Journal of Solids and Structures, vol.46, no.5, pp.1105-1120, 2009.

[21]T. Mori, K. and Tanaka. "Average stress in matrix and average elastic energy of materials with misfitting inclusions" Acta metallurgica, vol.21, no.5, pp.571-574, 1973.

[22] V.K. Karastathis, P.N. Karmis, G. Drakatos, et al. "Assessment of the dynamic properties of highly saturated concrete using one-sided acoustic tomography. Application in the Marathon Dam", Construction and Building Materials, vol.16, no.5, pp.261-269, 2002.

[23]J.S.Guo and P. Waldron, "An elastic model to quantify the effect of moisture on the mechanical properties of concrete at the time of test", Magazine of Concrete Research, vol.53, no.3, pp.151-162, 2001. 
[24]H.L. Wang and Q.B. Li, "Saturated concrete elastic modulus prediction", J Tsinghua Univ(Sci \& Tech), vol.45, no.6, pp.761-763, 2005.

[25]H.L. Wang and Q.B. Li, "Micro-mechanism of static and dynamic strengths for saturated concrete", SHUILI XUEBAO, vol.37, no.8, pp.958-962, 2006.

[26]H.L. Wang and Q.B. Li, "Mesomechanics analysis of conpressive strength and constitutive equation of wet concrete", Chinese Journal of Rock Mechanics and Engineering, vol.25, no.8, pp.1531-1536, 2006.

[27]H.L. Wang and Q.B. Li, "Effect of pore water on the compressive strength of wet concrete", ENGINEERING MECHANICS, vol.23, no.10, pp.141-145, 2006.

[28]H.L. Wang, Q.B. Li, X.Y. Sun, et al, "Mesomechanism of tensile strength reduction and tension constitutive model of saturated concrete", Journal of Basic Science and Engineering, vol.16, no.1, 2008.

[29] W.F. Bai, J.Y. Chen and S.L. Fan, “The Statistical Dynamic Damage Constitutive Model of Saturated Concrete under Uniaxial Tension", Journal of Disaster Prevention and Mitigation Engineering, vol.29, no.1, pp.16-21, 2009.

[30]Q. Yuan, C. Shi, De Schutter G, et al, "Numerical model for chloride penetration into saturated concrete", Journal of Materials in Civil Engineering, vol.23, no.3, pp.305-311, 2010.

[31]F. Bourgeois, J.F. Shao and O. Ozanam, "An elastoplastic model for unsaturated rocks and concrete", Mechanics Research Communications, vol.29, no.5, pp.383-390, 2002.

[32]S. Chatterji, An explanation for the unsaturated state of water stored concrete [J]. Cement and Concrete Composites, 2004, vol.26 (no.1): pp.75-79.

[33] S. Ghabezloo, "Association of macroscopic laboratory testing and micromechanics modelling for the evaluation of the poroelastic parameters of a hardened cement paste", Cement and Concrete research, vol.40, no.8, pp.1197-1210, 2010.

[34]L. Jin, X. Du and G. Ma, "Macroscopic effective moduli and tensile strength of saturated concrete", Cement and Concrete Research, vol.42, no.12, pp.1590-1600, 2012.

[35]X.L. Du and L. Jin, "Meso-element equivalent model for macro-scopic mechanical properties analysis of concrete materials", Chinese Journal of Computational Mechanics, vol.29, no.5, pp.654-661, 2012.

[36]X.X. Zheng, X.T. Zheng and L.H. Gou, "The research progress on multiscale method for the mechanical analysis of composites", Advances in Mechanics, vol.40, no.1, pp.41-56, 2010.

[37] J.B. Xing and L.Q. Yu, R.F. Zhang, "Experimen tal Verification of Meso-mechanical Beam-particle Model for Simulating Progressive Failure in Particulate Composite Materials", Journal of Experimental Mechanics, vol.13, no.3, pp.377-382, 1998.

[38]X.L. DU and L. Jin, "A review on meso-mechanical method for studying the static-mechanical properties of concrete", Advances in Mechanics, vol.41, no.4, pp.411-426, 2011.

[39] G.T. Liu and Z.M. Wang, "Numerical simulation study of fracture of concrete materials using random aggregate model”, J Tsinghua Univ(Sci \& Tech), vol.36, no.1, pp.84-89, 1996.

[40]P. Rossi, "Influence of cracking in the presence of free water on the mechanical behavior of concrete", Magazine of Concrete Research, vol.43, no.154, pp.53-57, 1991. 